\begin{tabular}{|l|l|l||}
\hline \multicolumn{2}{|c|}{ PublisherInfo } \\
\hline \hline PublisherName & $:$ & BioMed Central \\
\hline \hline PublisherLocation & $:$ & London \\
\hline \hline PublisherImprintName & $:$ & BioMed Central \\
\hline \hline
\end{tabular}

\title{
TNF-a suppresses CTGF expression
}

\begin{tabular}{|l|l|l||}
\hline \multicolumn{2}{|c|}{ ArticleInfo } \\
\hline \hline ArticleID & $:$ & 176 \\
\hline \hline ArticleDOI & $:$ & $10.1186 /$ ar-2000-66820 \\
\hline \hline ArticleCitationID & $:$ & 66820 \\
\hline \hline ArticleSequenceNumber & $:$ & 133 \\
\hline \hline ArticleCategory & $:$ & Paper Report \\
\hline \hline ArticleFirstPage & $:$ & 1 \\
\hline \hline ArticleLastPage & $:$ & 3 \\
\hline \hline & & RegistrationDate : 2000-6-20 \\
\hline ArticleHistory & $:$ & OnlineDate \\
\hline \hline ArticleCopyright & $:$ & Current Science Ltd2000-6-20 \\
\hline \hline ArticleGrants & $:$ & \\
\hline \hline ArticleContext & $:$ & 130753311 \\
\hline \hline
\end{tabular}




\section{John Campbell, ${ }^{\text {Aff1 }}$}

Aff1 University of Glasgow, UK

\section{Keywords}

Collagen, connective tissue growth factor, cytokine, fibroblast, scleroderma.

\section{Context}

Collagen deposition is an essential part of normal tissue development and wound healing; however, excessive accumulation of collagen is central to fibrotic disorders such as scleroderma. The pleiotropic cytokine TGF? is an essential cytokine in normal tissue development, necessary for fibroblast proliferation and induction of collagen deposition. Transiently elevated TGF? levels induce collagen deposition in normal wound healing, but TGF? continues to be expressed during uncontrolled fibrotic events. TGF? is essential for induction of CTGF production by fibroblasts, resulting in collagen deposition. CTGF is overexpressed in fibrotic disorders; therefore, understanding the factors that mediate its action may be important in understanding them. This paper investigated the ability of TNF-a to suppress TGF?-induced CTGF production in normal fibroblasts. TGF? induction and TNF-a suppression of CTGF expression by normal fibroblasts was found to act through the same promoter in the CTGF gene. In scleroderma patients CTGF was constitutively produced, was enhanced by TGF? and could not be ablated with TNF-a. To examine the role of TNF-a in suppressing TGF?-induced CTGF in fibroblasts.

\section{Significant findings}

CTGF protein was detected in TGF?-treated normal fibroblasts by western blotting and immunofluorescence. Addition of TNF-a before TGF? treatment stopped CTGF production. Collagen production by fibroblasts was also induced by TGFa and completely suppressed by TNF-a. TNF-a effects were mediated through NF-?B, demonstrated by cytokine signalling through the SEAP reporter construct and the ability of salicylic acid and SN50 to block TNF-a suppression of TGF?-mediated CTGF production. The element responsive to TNF-a and TGF? lay between nucleotides -166 and -244 , within the -805 to +17 nucleotide CTGF promoter construct. In contrast to normal cells, scleroderma lesional fibroblasts exhibited constitutive expression of CTGF protein, which could not be suppressed by TNF-a. TGF?-induced CTGF expression was suppressed in Scleroderma fibroblasts but this led to only a $50 \%$ reduction in induced collagen production. 


\section{Comments}

This paper demonstrates that tissue growth factor (TGF)?-induced production of connective tissue growth factor (CTGF) and collagen deposition by normal fibroblasts can be suppressed by tumour necrosis factor (TNF)-a. Furthermore, scleroderma fibroblasts constitutively produce CTGF, and this cannot be ablated by TNF-a. The findings are significant in two ways: firstly, constitutive expression of CTGF, and an increased sensitivity to TGF?, may underlie fibrosis in scleroderma; secondly, the discovery that TNF-a can regulate CTGF may open avenues to investigate control mechanisms in fibrotic diseases. Optimism must be tempered with the discovery that CTGF is not suppressed completely in scleroderma-derived cells, but this study provides the basis for future investigation. A possible criticism of the study is the comparison of scleroderma lesion fibroblasts with normal cells rather than cells from non-affected skin from the same patients. As a result it is not possible to determine whether the constitutive CTGF expression in scleroderma is an inherent, perhaps genetic, trait in the patients, or a phenomenon created by the unique lesional environment.

\section{Methods}

Fibroblasts were established in short-term culture from scleroderma skin lesions, healthy skin, and human foreskin. CTGF, vimentin and total protein levels were assessed by western blot and the actions of NF-?B blocked with cell-permeable peptide SN50. CTGF production was visualised using immunofluorescence in whole cells. A fragment of the CTGF promoter gene coupled to luciferase, and an NF-?B/I?B driven SEAP reporter gene, were transfected into NIH3T3 cells to assess responses to TNF-a and TGF?. CTGF promoter constructs of various lengths were produced by PCR, and cotransfected with a CMV-/-galactosidase gene to control for variations in transfection efficiency. Collagen type I was assayed by ELISA.

\section{References}

1. Abraham DJ, Shiwen X, Black CM, Sa S, Xu Y, Leask A: Tumour necrosis factor-a suppresses the induction of connective tissue growth factor beta in normal and scleroderma fibroblasts. J Biol Chem. 2000, 275: 15220-15225.

This PDF file was created after publication. 